\title{
THE NEUROBIOLOGY OF NARCOLEPSY-CATAPLEXY
}

\author{
Michael S. AldRICH \\ Department of Neurology, Sleep Disorders Center, University of Michigan Medical Center, Ann Arbor, \\ MI, U.S.A.
}

(Received 17 July 1992)

\section{CONTENTS}

1. Introduction

2. Clinical aspects

2.1. Sleepiness and sleep attacks

2.2. Cataplexy and related symptoms

2.3. Clinical variants

2.3.1. Narcolepsy without cataplexy

2.3.2. Idiopathic hypersomnia

2.3.3. Symptomatic narcolepsy

2.4. Treatment

3. Pathophysiology

4. Neurobiological studies

4.1. The canine model of narcolepsy

4.2. Pharmacology of human cataplexy

4.3. Postmortem studies

5. Genetic and family studies

6. Summary and conclusions

References

533
533
533
534
534
534
534
534
534
535
535
535
537
537
537
539
539

\section{INTRODUCTION}

Narcolepsy is a specific neurological disorder characterized by excessive sleepiness that cannot be fully relieved with any amount of sleep and by abnormalities of rapid eye movement (REM) sleep. About two-thirds of patients also have brief episodes of muscle weakness usually brought on by emotion, referred to as cataplexy. The disorder generally begins in adolescence and continues throughout life.

Over the past three decades, there has been remarkable progress in understanding the fundamental mechanisms responsible for narcoleptic symptoms. Narcolepsy is associated with the premature onset of REM sleep and studies of the neuroanatomical and neurochemical substrate of REM sleep, combined with pharmacological, physiological, genetic and molecular studies of narcolepsy have led to striking advances. This article provides an overview of the clinical syndrome followed by a presentation of current views of its pathophysiology and neurobiology.

Address correspondence to M. S. Aldrich, Sleep Disorders Center, Department of Neurology Taubman Center 1920/0316, University of Michigan Medical Center, 1500 East Medical Center Drive, Ann Arbor, MI 48109-0316, U.S.A.

\section{CLINICAL ASPECTS}

Narcolepsy has a prevalence that varies worldwide from as little as $0.0002 \%$ in Israel to $0.16 \%$ in Japan; in North America and Europe the prevalence is about 0.03-0.06\% (Dement et al., 1972; Honda, 1979; Lavie and Peled, 1987). The onset of narcoleptic symptoms, usually in the second or third decade of life, may occur over a few days or weeks or it may be so gradual that the loss of full alertness is unrecognized by family or friends. The onset may be attributed to a variety of antecedent events including psychological or physical stress, minor or major head trauma, infections, drug abuse, or pregnancy, but whether these precipitants contribute to development of the syndrome or are just coincidental is uncertain.

\subsection{SLeEPINESS AND SleEP AtTaCKS}

Excessive sleepiness and cataplexy are not the only symptoms of narcolepsy but they are usually the most troublesome. Sleepiness is more characteristic than an increase in actual sleep time; the amount of sleep obtained over $24 \mathrm{hr}$ is increased only slightly because the daytime sleep episodes are offset by frequent nocturnal awakenings.

Narcoleptic sleepiness is similar to the sleepiness that occurs with sleep deprivation in normal people: it is most apparent in boring, sedentary situations and is partially relieved by stimulation or movement. Narcoleptic sleepiness fluctuates from minute to minute and varies between patients: it may be mild 
and easily overcome by stimulation or it may be severe and overwhelming as soon as the patient sits down. The inability to obtain full alertness after any amount of night-time or daytime sleep is the feature that distinguishes narcoleptic sleepiness from sleepiness associated with sleep deprivation.

Although spontaneous daytime sleep episodes may appear paroxysmal, similar to epileptic seizures, they are preceded by electrophysiological evidence of increasing drowsiness; thus sleep "attacks" are simply episodes of falling asleep. Because narcoleptics lack personal experience of full alertness and become habituated to chronic drowsiness, they may not perceive sleepiness in the usual way; this lack of awareness probably accounts for descriptions of "sleep attacks".

Chronic sleepiness leads to memory disturbances, visual problems and episodes of amnesia lasting for seconds to 30 minutes or more, associated with semi-purposeful activity, referred to as automatic behavior. Memory problems are probably caused by drowsiness and brief episodes of sleep with associated impaired attention and concentration rather than by a specific disturbance of brain regions involved in memory. Failure of fusion induced by drowsiness in exophoric patients is the likely cause of blurred and double vision. Episodes of automatic behavior usually occur during monotonous or repetitive activities and may be associated with brief pauses in speech or movement, irrelevant words or remarks and nonsensical activities.

\subsection{Cataplexy and Related Symptoms}

Brief episodes of weakness brought on by excitement or emotion, called cataplexy, occur in about two-thirds of patients and are almost unique to narcolepsy. Precipitants of cataplexy include laughter, anger, embarrassment, excitement and athletic activities. With severe attacks, there is complete atonic areflexic paralysis of striated muscles sparing only respiratory muscles; the more common milder episodes can cause facial weakness, slurred speech, drooping eyelids, weakness of grip, head nodding, or slight buckling at the knees. Episodes last from a few seconds to several minutes; consciousness is not impaired initially but longer episodes may be associated with auditory, visual, or tactile hallucinations and the onset of REM sleep.

Two other symptoms, sleep paralysis and hypnagogic hallucinations, are common in narcolepsy. Sleep paralysis refers to episodes occurring at sleep onset or upon awakening of inability to move, sometimes associated with a sensation of struggling to move or awaken. They last up to several minutes and end spontaneously or after mild stimulation. Hypnagogic hallucinations also occur during the transitions between sleep and wakefulness. They resemble dreams in that the apparent reality of visual, tactile, or auditory features is usually unquestioned, but they differ because some awareness of the environment is preserved. Unlike cataplexy, sleep paralysis and hypnagogic hallucinations can occur in otherwise normal people after sleep deprivation or a change in sleep schedule.

\subsection{Clinical Variants}

\subsubsection{Narcolepsy without cataplexy}

In the one-third of patients with narcolepsy who do not have cataplexy, age of onset, premature occurrence of REM sleep and severity of sleepiness are similar to patients with narcolepsy-cataplexy, but sleep paralysis, hypnagogic hallucinations and severe nocturnal sleep disruption are less common (Rosenthal et al., 1990). As cataplexy may develop decades after the onset of sleepiness, the eventual occurrence of cataplexy can never be excluded in a given patient. Genetic and family studies (see below) suggest that narcolepsy without cataplexy is probably a less severe manifestation of the same disorder.

\subsubsection{Idiopathic hypersomnia}

Patients with this syndrome have excessive sleepiness without cataplexy or abnormalities of REM sleep. Although the syndrome is unrelated to narcolepsy in most cases, its occurrence in some family members of narcoleptics and the fact that some patients with this syndrome eventually develop cataplexy and REM sleep abnormalities suggest that occasionally it may be a variant of narcolepsy.

\subsubsection{Symptomatic narcolepsy}

Acquired brain lesions as a cause of narcolepsy have been of interest since cases of narcolepsy were described following the epidemic of encephalitis lethargica more than 60 years ago. Although post-encephalitic narcolepsy is now extremely rare, either from death of affected patients or a change in disease patterns, narcolepsy can develop in association with brain lesions adjacent to the third ventricle, an area concerned with sleep-wake regulation (see Aldrich and Naylor, 1989 for review). Although many such patients have the HLA marker associated with idiopathic narcolepsy (see below), this is not enough to suggest that narcolepsy can occasionally arise from brain lesions alone in the absence of the usual genetic substrate.

\subsection{TREATMENT}

Although narcoleptic symptoms respond to medication, they are usually not fully controlled. Thus, maintaining alertness and avoiding cataplexy during specified times of the day, such as during work, school, or driving, are the main goals of therapy. For sleepiness, amphetamines and related compounds such as methylphenidate and pemoline are the most effective medications. Many clinicians also recommend one or more short naps each day; such naps often provide a period of relative alertness lasting 1-2 hr. Tricyclic anti-depressants are the most effective medication for the treatment of cataplexy and permit almost complete control of the symptoms in about $80 \%$ of patients. However, patients with severe cataplexy may develop tolerance to their effects and a temporary withdrawal of medication may be required to restore efficacy. Abrupt discontinuation of anti-cataplectic medication can lead to nearly con- 
tinuous incapacitating cataplexy lasting for several hours or days.

\section{PATHOPHYSIOLOGY}

Although the essential clinical features of narcolepsy have been known for more than 100 years, the discovery in the 1960 s that patients with narcolepsy have a remarkable predisposition to enter directly into rapid eye movement (REM) sleep at the onset of sleep provided the first clue to its pathophysiology and neurobiology (Rechtschaffen et al., 1963; Takahashi and Jimbo, 1963; Vogel, 1960). As REM sleep usually begins about $80-100$ minutes after the onset of REM sleep, the tendency to enter REM sleep within minutes of falling asleep provides a useful diagnostic tool for narcolepsy as well as an indication that impaired control and regulation of REM sleep are key features of its pathogenesis.

REM sleep is characterized by cortical activation with low amplitude desynchronized EEG activity, skeletal muscle atonia and rapid eye movements. Compared with NREM sleep, brain metabolic activity is increased and there is greater variability of heart rate, blood pressure and respiration; it is the state in which most dreams occur. Evidence collected over the past three decades has provided strong indications that many of the symptoms of narcolepsy are due to intrusion of elements of REM sleep into the waking state. Thus, the weakness associated with cataplexy and the immobility that occurs with sleep paralysis are associated with muscle atonia that is physiologically almost indistinguishable from the atonia of REM sleep. Similarly, hypnagogic hallucinations probably represent dream imagery occurring at the interface between wakefulness and sleep.

However, disordered REM sleep is not the sole pathophysiological feature of narcolepsy. Many daytime sleep episodes consist only of NREM sleep suggesting that there is a broader problem of impaired sleep-wake regulation. Frequent nocturnal awakenings indicate an impaired ability to sustain sleep that complements the daytime inability to remain awake. Periods of sleep that have physiological features of REM and NREM sleep, along with evidence that an element of wakefulness is often still present during sleep onset REM periods (Hishikawa, 1975), suggest that narcolepsy is associated with indistinct boundaries between wakefulness, REM sleep and NREM sleep (Broughton et al., 1986). Episodes of REM sleep without the usual associated muscle atonia and the occurrence in some patients of the REM sleep behavior disorder (Schenk et al., 1989) support the notion that the sleep-wake state boundaries are impaired.

\section{NEUROBIOLOGICAL STUDIES}

The relation between impaired regulation of REM sleep and clinical symptomatology suggests that abnormal activity of neural systems involved in REM sleep may contribute to the pathogenesis of narcolepsy. As shown by studies using transections, lesions and stimulation techniques, the essential el- ements for the generation of REM sleep are located in the pons. The rostral pontine tegmentum and areas adjacent to and within the locus coeruleus contain neurons, referred to as "REM-on" cells, that are selectively activated during REM sleep and that are essential for its expression (Sakai, 1988; Siegel, 1989). Muscarinic agonists injected into the pontine tegmentum facilitate the appearance of a REM sleep-like state in a dose-dependent and site-dependent manner (Baghdoyan et al., 1984; Vanni-Mercier et al., 1989); these and other studies have demonstrated that many of the REM-on neurons are almost certainly cholinergic and that cholinergic neurons play a central role in the generation of REM sleep. The muscarinic receptor M2 subtype appears to be largely responsible for the REM sleep-inducing effects of muscarinic agonists, although $\mathrm{M} 1$ and $\mathrm{M} 3$ receptor subtypes may play minor roles (Imeri et al., 1991; VelazquezMoctezuma et al., 1989, 1991).

Located within the same regions as pontine REMon cells are REM-off cells, cells that are selectively silent during REM sleep. Many of these REM-off neurons, such as serotonergic neurons of the raphe nuclei and noradrenergic neurons of the locus coeruleus, are monoaminergic and appear to play a permissive role through modulation of activity of REM-on neurons (Jones, 1991; Siegel, 1989).

Two areas of the medulla are critically involved in the expression of muscle atonia during REM sleep, the nucleus magnocellularis and the nucleus paramedianus (Lai and Siegel, 1988). Certain cells in these regions have high rates of discharge in REM sleep with lower discharge rates during NREM sleep and wakefulness (Siegel, 1989). Atonia can be induced by stimulation of these regions: glutamate induces atonia in the nucleus magnocellularis via non- $N$-methylD-aspartate receptors whereas acetylcholine induces atonia in the nucleus paramedianus via muscarinic receptors (Lai and Siegel, 1988; Lai and Siegel, 1991). These regions appear to mediate REM sleep atonia and the atonia induced by infusion of muscarinic agonists into the pontine tegmentum.

\subsection{The Canine Model of Narcolepsy}

The existence of an animal model of narcolepsy, discovered in the early 1970 s, has permitted extensive investigations of this condition. Canine narcolepsy is characterized by juvenile onset of sleep-onset REM periods, cataplexy, excessive sleepiness and sleep-wake abnormalities similar to those seen in human narcolepsy (Foutz et al., 1981; Kaitin et al., 1986; Kushida et al., 1985; Lucas et al., 1979; Mitler and Dement, 1977). Cataplexy in these animals is readily precipitated by food, a response that has been standardized as the food elicited cataplexy test (FECT) (Delashaw et al., 1979).

Studies using the FECT have demonstrated that four classes of compounds exacerbate cataplexy (Table 1). Cataplexy is associated with increased acetylcholine release in the medial pontine reticular formation and infusions of muscarinic M2 receptor agonists, but not M1 receptor agonists, into the medial pontine reticular exacerbates cataplexy (Reid et al., 1992).

Several classes of drugs inhibit cataplexy; the most 
Table 1. Receptor Pharmacology of Canine Cataplexy

\begin{tabular}{|c|c|c|}
\hline Site of action & Exacerbate cataplexy & Inhibit cataplexy \\
\hline $\begin{array}{l}\text { Noradrenergic alpha-1 receptor } \\
\text { Noradrenergic alpha-2 receptor } \\
\text { Dopaminergic D-1 receptor } \\
\text { Dopaminergic D-2 receptor } \\
\text { Muscarinic receptor }\end{array}$ & $\begin{array}{c}\text { Antagonists }(\alpha 1 \mathrm{~b}>\alpha \text { la) } \\
\text { Agonists (non-imidazole type) } \\
- \\
\text { Agonists }^{3} \\
\text { Agonists }^{5}\end{array}$ & $\begin{array}{l}\text { Agonists }^{2} \\
\text { Antagonists } \\
\text { Antagonists } \\
\text { Antagonists } \\
\text { Antagonists }\end{array}$ \\
\hline
\end{tabular}

References: 1. Mignot et al., 1988; Mignot et al., 1989; 2. Nishino et al., 1992; 3, Nishino et al., 1990;

4. Nishino et al., 1991; 5. Delashaw et al., 1979; Foutz et al., 1981.

potent effects are produced by drugs that increase synaptic availability of norepinephrine by blocking reuptake or by enhancing release (Table 1). Although fluoxetine and other serotonergic reuptake inhibitors also inhibit cataplexy, their effects are probably mediated at least in part by their aminated metabolites, which inhibit norepinephrine reuptake (Nishino et al., 1992). Furthermore, the efficacy of tricyclic anti-depressants in the treatment of canine cataplexy is directly proportional to their inhibition of norepinephrine reuptake (Foutz et al., 1981). Compounds that increase synaptic availability of dopamine have little effect on cataplexy (Nishino et al., 1990, 1991; Renaud et al., 1991), but dopamine D1 and D2 receptor antagonists are inhibitory, perhaps by acting at presynaptic receptors on noradrenergic neurons. Cataplexy can also be inhibited by prosta- glandin E2 and its methyl ester (Nishino et al., 1989).

Siegel et al. (1991), recording single unit activity from the medial medulla during canine cataplectic attacks, identified cells that were activated during cataplexy (Fig. 1). The cataplexy-on cells, which were not cholinergic and which were in the same region as the glutamate sensitive cells mediating atonia described above, were active during REM sleep; however, most REM-on cells were not activated during cataplexy.

These studies support the view that cataplexy is physiologically and pharmacologically closely related to REM sleep. The premature onset of REM sleep in narcolepsy and the intrusion of muscle atonia into wakefulness that occurs with cataplexy could be a result of inadequate monoaminergic inhibition of

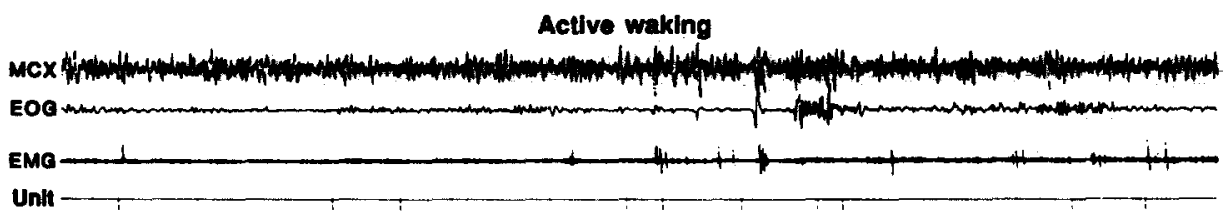

Waking/cataplexy
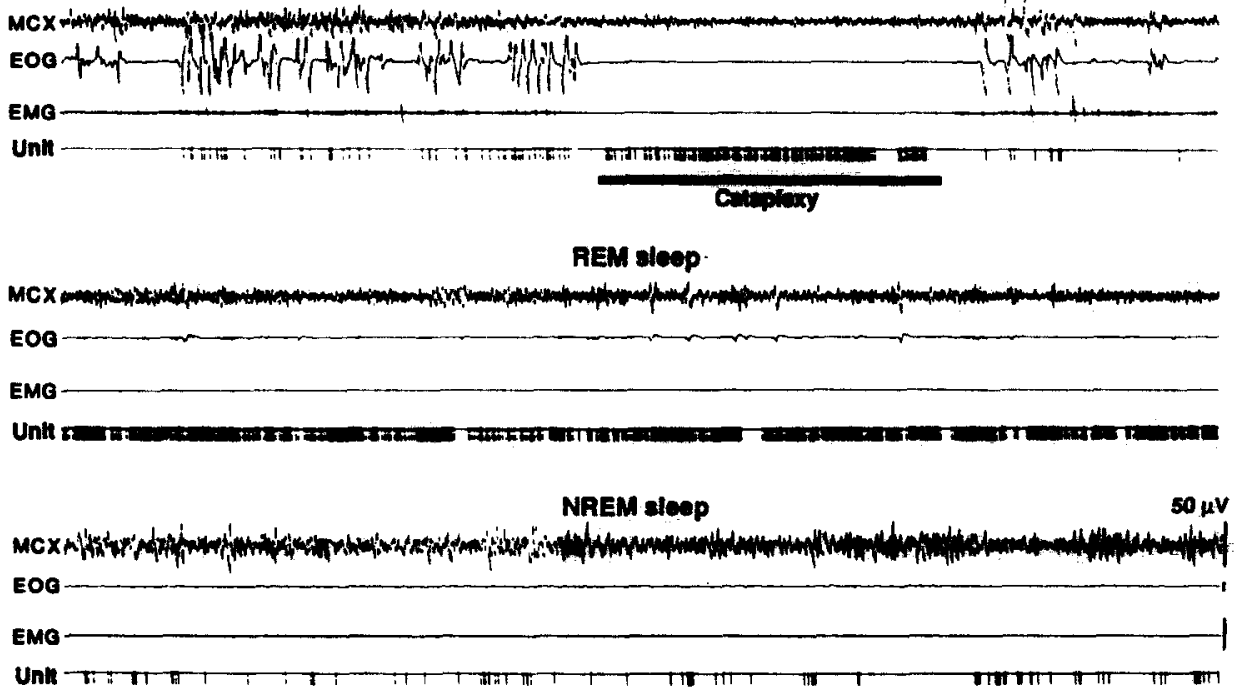

10

FIG. 1. Single-unit activity from the medial medulla of a narcoleptic dog recorded during wakefulness, non-REM sleep, REM sleep and cataplexy elicited by play or food. The unit is selectively activated during REM sleep and during cataplexy. Only a fraction of REM-on cells are activated during cataplexy. Reproduced with permission from Siegel et al. (1991). 
cholinergic REM sleep mechanisms or of excessive excitation of cholinergic or glutamatergic brainstem systems.

\subsection{Pharmacology of Human Cataplexy}

The clinical pharmacology of human cataplexy is consistent with the canine model. Amphetamines and related stimulants, commonly used to treat narcoleptic sleepiness, increase synaptic availability of norepinephrine. Prazosin, a noradrenergic alpha-1 receptor antagonist, causes an exacerbation of human cataplexy (Aldrich and Rogers, 1989; Guilleminault et al., 1988) whereas tricyclic anti-depressants that block norepinephrine reuptake inhibit cataplexy. Although cataplexy is also inhibited by fluoxetine (Langdon et al., 1986), a relatively specific blocker of 5-HT reuptake, the inhibition may be due to the effects of its primary metabolite, norfluoxetine, which is active at noradrenergic synapses. Drugs that increase synaptic availability of dopamine have relatively little effect on cataplexy and other narcoleptic symptoms despite the finding that cerebrospinal fluid levels of dopamine and its metabolite homovanillic acid are reduced in sufferers of human narcolepsy (Montplaisir and Godbout, 1986; Parkes et al., 1974). These findings are consistent with the view that defective noradrenergic modulation of REM sleep mechanisms contributes to human and canine narcolepsy. As noradrenergic projections systems are also intimately involved in maintenance of wakefulness, a defect in noradrenergic metabolism may also contribute to a broader problem of sleep/wake regulation.

\subsection{PostMortem Studies}

Postmortem studies of human narcoleptic brain tissue have not shown consistent structural lesions at the light microscopic level. Neurochemical studies, however, suggest that monoaminergic function is abnormal. Binding of ligands specific for dopamine $\mathrm{D} 1$ and D2 receptors is increased in areas of the striatum (Aldrich et al., 1992; Kish et al., 1992). Preliminary studies suggest that there may also be an alteration in the balance of adrenergic alpha-2 and alpha-1 receptors in selected brain regions (Aldrich et al., 1991). Studies of the norepinephrine metabolite 3-methoxy-4-hydroxyphenylglycol (MHPG) and of the serotonin metabolite 5-hydroxyindoleacetic acid (5-HIAA) have shown increased concentrations and a trend towards increased ratios of monoamine metabolites to neurotransmitters in a number of brain regions (Kish et al., 1992). While medication taken before death may have contributed to these findings, there is the suggestion of augmented monoamine turnover and increased monoaminergic nerve terminal activity in at least some brain areas (Kish et al., 1992).

Studies of canine narcoleptic brain have also shown neurochemical abnormalities such as: (1) increased numbers of muscarinic receptors, probably of the M2 subtype, in the brainstem nucleus reticularis gigantocellularis (Kilduff et al., 1986); (2) increased dopamine D2 receptors in the amygdala (Bowersox et al., 1987); (3) increased alpha-2 adrenoceptors in the locus coeruleus (Fruhstorfer et al., 1989); (4) increased concentrations of dopamine and 3,4-dihydroxyphenylacetic acid (DOPAC) in the amygdala (Miller et al., 1990); and (5) increased concentrations of norepinephrine in portions of the brainstem (Miller et al., 1990). Preliminary studies suggest that there are no major changes in adenosine or benzodiazepine receptors (Bowersox et al., 1986; Hawkins et al., 1991). While these studies are not conclusive, they are similar to the findings in human narcoleptic brain and suggest an alteration in cholinergic and monoaminergic metabolism.

\section{GENETIC AND FAMILY STUDIES}

Although the occurrence of narcoleptic symptoms among family members of persons with narcolepsy has been recognized for many years (Baraitser and Parkes, 1978; Daly and Yoss, 1959; Kessler et al., 1974), the prevalence of confirmed narcolepsy among family members, as opposed to subjective complaints of sleepiness, is only about $1 \%$ (Guilleminault $e t$ al., 1989). Only $3 \%$ of narcoleptics have a first degree relative with narcolepsy and only one-third of those, or $1 \%$ of all narcoleptics, have more than one affected first degree relative (Guilleminault et al., 1989). The risk of developing narcolepsy is about 18 times greater in first degree relatives of narcoleptics than in the normal population (Guilleminault et al., 1989). This mode of inheritance is consistent with an autosomal dominant pattern with low penetration.

The first clues to the genetic basis of narcolepsy were provided by studies of Class II human leukocyte antigens (HLA). Expression of these antigens is governed by the major histocompatibility complex (MHC) on chromosome 6 (Fig. 2). Studies performed in the $1980 \mathrm{~s}$, initially in Japan and subsequently in Europe, North America and Africa, demonstrated that the HLA-DR2 antigen, found in $20-35 \%$ of the normal population, has an incidence that exceeds $95 \%$ in European and Caucasian patients with narcolepsy and is close to $100 \%$ in Japanese patients (Billiard and Seignalet, 1985; Juji et al., 1984, 1988; Kramer et al., 1987; Langdon et al., 1984). There is also an extremely high incidence of HLA-DQw1, equaling or exceeding that of HLA-DR2 in all narcoleptic groups assessed to date. In African-Americans with narcolepsy HLA-DR2 is found in only about $65 \%$ but HLA-DQw1 is present in more than $90 \%$ (Matsuki et al., 1992; Neely et al., 1987). These studies strongly suggest that a gene in close proximity to the HLA-DR and DQ regions has a major role in the pathogenesis of narcolepsy. The HLA-DP region is not involved in the narcoleptic haplotype (Olerup, 1990).

In patients with narcolepsy who do not have cataplexy, the DR2 marker occurs almost as frequently as it does in narcolepsy-cataplexy syndrome (see Aldrich, 1992), suggesting phenotypic variability for the HLA associated susceptibility gene or genes. The occurrence of idiopathic hypersomnia in some DR2 positive relatives of narcoleptics suggests that some cases of this entity may represent a third phenotype (Harris et al., 1987).

Recent analyses have permitted subtyping of the HLA-DR2 antigen into DRw15 and DRw16 sub- 


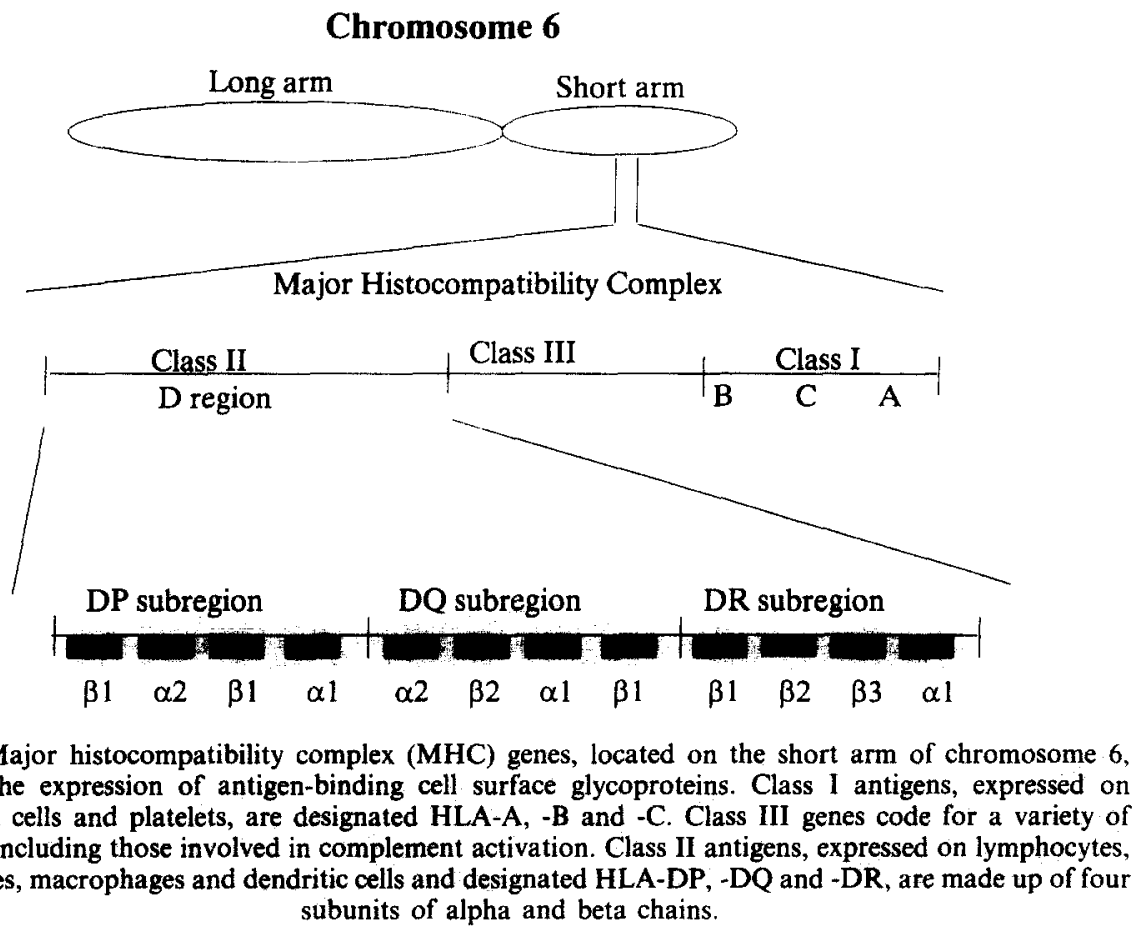

types. In addition, the DQw6 subtype of DQw1 has been identified. The DRw15 and DQw6 subtypes are strongly associated with narcolepsy as is the Dw2 antigen, which is detected with mixed lymphocyte cultures rather than by serologic testing (Honda et al., 1986; Juji et al., 1988). The DRw15/DQw6/Dw2 haplotype is carried by more than $90 \%$ of narcoleptics and is specifically associated with susceptibility to narcolepsy, not to the symptom of somnolence, as its incidence is not increased in sleep apnea or in other disorders causing excessive sleepiness (Rubin et al., 1988).

The DRw15/DQw6/Dw2 haplotype encompasses several polymorphic genes, named DRB1-1501, DQA1-0102 and DQB1-0602, that encode the DRw15 and DQw6 antigens. Two of these, DRB11501 and DQB1-0602, occur only with the DRw15/DQw6/Dw2 haplotype in Caucasian and Japanese populations and are therefore potential candidates for the HLA-related narcolepsy susceptibility gene. However, in African and AfricanAmerican subjects, some haplotypes show a dissociation between DRB1-1502 and DQB1-0602. Matsuki et al. found that the DQB1-0602 gene was present in $100 \%$ of African-American narcoleptics but in only $38 \%$ of control African-Americans (Matsuki et al., 1992). The DQB1-0602 was present even in subjects who did not carry DRw15. These findings suggest the possibility that the HLA-related narcolepsy susceptibility gene is identical to the DQB10602 gene. However, other genes closely linked to DQB $1-0602$ could also be responsible and remain to be investigated.

Attempts to identify a unique DNA sequence conferring susceptibility to human narcolepsy have so far been unsuccessful. Restriction fragment length polymorphisms (RFLPs) for DR(beta), DQ(alpha) and DQ(beta) are identical in narcoleptics and controls with DRw15/DQw6/Dw2 haplotypes (Holloman et al., 1987; Honda et al., 1986; Kuwata et al., 1991; Lock et al., 1988; Olerup et al., 1990; Uryu et al., 1989; Wilner et al., 1988). These findings and evidence that the HLA marker came from different ancestral sources in some familial cases (Guilleminault et al., 1989) suggests that narcoleptic susceptibility is not caused by a mutation of the genes responsible for the DRw15/DQw6/Dw2 haplotype.

The occurrence of the DRw15/DQw6/Dw2 haplotype in asymptomatic relatives of narcoleptics and in control subjects and the presence of DQB1-0602 in almost $40 \%$ of asymptomatic African-Americans provides strong evidence that the HLA-related susceptibility gene is not sufficient to induce narcolepsy. Concordance for narcolepsy is rare in monozygotic twins (Guilleminault et al., 1989; Montplaisir and Poirier, 1987), indicating that unknown environmental factors play a major role in the development of narcolepsy.

Despite the strong association of HLA markers with narcolepsy, increasing evidence suggests that the syndrome is genetically heterogeneous. There are well documented cases of DR2/DQw1 negative narcolepsy and in some narcoleptic families with two or more affected individuals, not all narcoleptics carry the DRw15/DQw6/Dw2 haplotype. In other families, all affected members are negative for HLA-DR2 (Dahlitz et al., 1992; Guilleminault et al., 1989; Singh et al., 1990) and studies of DNA band patterns from the HLA region generated by a number of restriction enzymes in two such families suggested that there had been no recombination in the HLA region and that the occurrence of narcolepsy was unrelated to. HLA haplotype (Ditta et al., 1992). Thus, a gene unrelated to the HLA region appeared to be responsible, 
suggesting that narcolepsy is genetically heterogeneous.

The inheritance of canine narcolepsy in Doberman pinschers and Labrador retrievers is consistent with the presence of a single fully penetrant autosomal recessive gene, designated canarc- 1 . This gene is not linked to the canine equivalent of the MHC region (Dean et al., 1989; Matoyama et al., 1989); instead it is tightly linked to a polymorphic DNA band that is strongly homologous with the human switch region of the mu immunoglobulin heavy-chain gene (Mignot et al., 1991b), which is involved in determining the immunoglobulin class of certain activated B-lymphocytes.

Although full expression of canine narcolepsy and spontaneous cataplexy requires homozygosity for canarc-1, cataplexy may develop in heterozygotes following administration of a combination of physostigmine, a muscarinic agonist and prazosin, an adrenergic alpha-1 antagonist (Mignot et al., 1991 a). This biological activity of a single copy of canarc-1 suggests that this gene, if present in humans, could contribute to narcolepsy susceptibility. However, in preliminary studies of five families in which narcoleptic susceptibility was not associated with HLA haplotype, narcolepsy was not associated with unique RFLP patterns generated by the mu-switch $\mathrm{H}-24$ genomic probe gene, suggesting that the genes in the immunoglobulin heavy chain locus do not contribute to susceptibility to human narcolepsy (George $e t$ al., 1992).

Although the associations of human narcolepsy with the HLA-D region and canine narcolepsy with the immunoglobulin mu-switch region suggests that narcolepsy may have an immunologic pathogenesis, there is little evidence of immunologic abnormalities in human narcolepsy (Frederikson et al., 1990; Honda et al., 1986; Rubin et al., 1988; Strohmaier et al., 1988). The onset of canine cataplexy is associated with a mild CSF pleocytosis (Gaiser et al., 1989) and it remains possible that a transient immune mediated event that is not readily detectable is involved in the initiation of human narcolepsy.

\section{SUMMARY AND CONCLUSIONS}

Human narcolepsy is a chronic neurological disorder characterized by excessive daytime sleepiness, episodic muscle weakness (cataplexy), premature onset of rapid eye movement (REM) sleep and impaired sleep-wake regulation. A canine model for narcolepsy exists that shows many physiological, pharmacological and behavioral similarities to the human disease. Neurobiological studies of human and canine narcolepsy suggest that abnormal regulation of REM sleep, probably related to disturbed monoaminergic and cholinergic brainstem activity, accounts for much of narcoleptic symptomatology.

Genetic and family studies have demonstrated a strong association of human narcolepsy with the HLA haplotype DRw15/DQw6/Dw2 and with the DQB 1-0602 gene in the HLA region. The two main phenotypes of narcolepsy-narcolepsy-cataplexy syndrome and narcolepsy without cataplexy-are both strongly associated with the HLA markers.
However, the existence of some families in which narcolepsy does not cosegregate with HLA haplotypes suggests genetic heterogeneity with the existence of a second narcolepsy susceptibility gene unrelated to the HLA region. This second gene is probably not the fully penetrant autosomal recessive gene, designated canarc-1, that is responsible for the narcolepsy that occurs in some large canine breeds. Discordance for narcolepsy in monozygotic twins indicates that environmental factors are required for full expression of the syndrome.

Despite the striking advances reviewed in this manuscript, many aspects of narcolepsy remain unclear including the precise identity and function of the HLA-associated susceptibility gene and the additional gene that is implicated in families in which narcolepsy does not cosegregate with HLA haplotypes. The additional environmental, developmental and genetic factors that lead to disease expression and contribute to phenotypic variability are unknown. The function of the recessive gene responsible for canine narcolepsy is unknown as is the role, if any, of the homologous human gene. Although neurochemical and neuropathological studies implicate a derangement of noradrenergic metabolism, it is uncertain whether these changes are primary or secondary. Research that sheds light on these uncertainties may help to identify more effective treatments for this chronic disorder.

\section{REFERENCES}

ALDRICH, M. S. (1992) Narcolepsy. Neurology 42(Suppl. 6), $34-43$. ALDRICH, M. S. and NAYLOR, M. W. (1989) Narcolepsy associated with lesions of the diencephalon. Neurology 39, 1505-1508.

ALDRICH, M. S. and Rogers, A. E. (1989) Exacerbation of human cataplexy by prazosin. Sleep 12, 254-256.

Aldrich, M. S., Hollingsworth, Z. and Penney, J. B. (1991) Adrenergic receptor autoradiography of human narcoleptic brain. Sleep Res. 20A, 280.

Aldrich, M. S., Hollingsworth, Z. and Penney J. B. (1992) Dopamine receptor autoradiography of human narcoleptic brain. Neurology 42, 410-415.

Baghdoyan, H. A., Rodrigo-Angulo, M. L., McCarley, R. W. and HoBson, J. A. (1984) Site-specific enhancement and suppression of desynchronized sleep signs following cholinergic stimulation of three brainstem regions. Brain Res. 306, 39-52.

Barattser, M. and PARKES, J. D. (1978) Genetic study of the narcoleptic syndrome. J. Med. Genet. 15, 254-259.

Billiard, M. and Seignalet, J. (1985) Extraordinary association between HLA-DR2 and narcolepsy. Lancet 2, 226-227.

Bowersox, S. S., Kilduff, T. S., Kaitin, K. I., Dement, W. C. and Ciarenello, R. D. (1986) Brain benzodiazepine receptor characteristics in canine narcolepsy. Sleep 9, 111-115.

Bowersox, S. S., Kilduff, T. S., Faull, K. F., Zeller-DeAmicis, L., Dement, W. C. and Ciarenello, R. D. (1987) Brain dopamine receptor levels elevated in canine narcolepsy. Brain Res. $\mathbf{4 0 2}$, 444-448.

Broughton, R., Valley, V., Aguirre, M., Robert, J., Suwalski, W and Dunham, W. (1986) Excessive daytime sleepiness and the pathophysiology of narcolepsy-cataplexy: a laboratory perspective. Sleep 9, 205-215.

Dahlitz, M., Vaughan, R., Kayed, K. and Parkes J. D. (1992) The narcolepsy susceptibility gene. Lancet 339, 1297.

Daly, D. D. and Yoss, R. E. (1959) A family with narcolepsy. Proc. Mayo Clin. 34, 313-319.

Dean, R. R., KildufF, T. S., Dement, W. C. and Grumet, F. C. (1989) Narcolepsy without unique MHC Class II antigen association: studies in the canine model. Hum. Immun. 25, 27-35.

Delashaw, J. B., Foutz, A. S., Guilleminault, C. and Dement, W. 
(1979) Cholinergic mechanisms and cataplexy in dogs. Exp. Neurol. 66, 745-757.

Dement, W., Zarcone, V., VARNer V. el al. (1972) The prevalence of narcolepsy. In: Sleep Research, Vol. 1, p. 148. Eds. M. H. ChaSE, W. C. STERN and P. L. WAL.TER. Brain Information Service/Brain Research Institute, UCLA: Los Angeles.

Ditta, S. D., George, C. F. P. and Singh, S. M. (1992) HLA-D-region genomic DNA restriction fragments in DRw15(DR2) familial narcolepsy. Sleep 15, 48-57.

Foutz, A. S., Delashaw, J. B., Gulleminault, C. and Dement, W. C. (1981) Monoaminergic mechanisms and experimental cataplexy. Ann. Neurol. 10, 369-376.

Frederikson, S., Carlander, B., Billiard, M. and Link, H. (1990) CSF immune variables in patients with narcolepsy. Acta neurol. scand. 81, 253-254.

Fruhstorfer, B., Mignot, E., Bowersox, S., Nishino, S. and DEMENT, W. C. (1989) Canine narcolepsy is associated with an elevated number of alpha 2-receptors in the locus coeruleus. Brain Res. 500, 209-214

Gaiser, C., Burtch, M., Radde, L., Dement, W. and Steinman, L (1989) Evidence for an autoimmune etiology in canine cataplexy. Sleep Res. 18, 230.

George, C. F. P.. Ott, R. N., Singh, S. M., Gelb, M., Grumet, F. C. and MigNOT, E. (1992) IgM (mu switch) region restriction fragment length polymorphism in human familial narcolepsy. Sleep Res. 21, 201

Gullleminault, C., Mignot, E., Aldrich, M., Quera-Salva, M. A., Tiberge, M. and Partinen, M. (1988) Prazosin contraindicated in patients with narcolepsy. Lancet 2, 511

Gullleminalut, C., Mignot, E. and Grumet, F. C. (1989) Familial patterns of narcolepsy. Lancet 2, 1376-1379.

Harris, L., Douglass, A. B., Pazderka, F. and Dossetor, J. B. (1987) Patterns of HLA-DR2 inheritance in families with narcolepsy and hypersomnolence. Sleep Res. 16, 347.

Hawkins, M., O'Connor, S., Radulovacki, M., Bowersox, S., Mignot, E. and Dement, W. (1991) Radioligand binding to adenosine receptors and adenosine uptake sites in different brain regions of normal and narcoleptic dogs. Pharmac. Biochem. Behav. $38,1-6$.

HishikaWA, Y. (1975) Sleep paralysis. In: Narcolepsy, pp. 97-124. Eds. C. Guilleminault, W. C. Dement and P. Passouant, Spectrum: New York.

Holloman, J. D., Bell, J. I., Kilduff, T. S., Dement, W. C., Guilleminaul T, C. and MCDevitT, H. O. (1987) HLA-DR restriction-fragment-length polymorphisms in narcolepsy. $J$. Neurosci. Res. 18, 239-244.

Honda, Y. (1979) Census of narcolepsy, cataplexy and sleep life among teenagers in Fujisawa city. Sleep Res. 8, 191.

Honda, Y., Juji, T., Matsuki, K., Naohara, T., Satake, M., Inoko, H., Someya, T., Harada, S. and DoI, Y. (1986) HLA-DR2 and Dw2 in narcolepsy and in other disorders of excessive somnolence without cataplexy. Sleep 9, 133-142.

IMERI, L., BIANCHI, S., ANGeli, P. and MaNCIA, M. (1991) Differential effects of M2 and M3 muscarinic antagonists on the sleep-wake cycle. Neuro. Rep. 2, 383-385.

Jones, B. E. (1991) Paradoxical sleep and its chemical/structural substrates in the brain. Neuroscience 40, 637-656.

Juji, T., Satake, M., Honda Y. and Dor, Y. (1984) HLA antigens in Japanese patients with narcolepsy-all the patients were DR2 positive. Tissue Antigens 24, 316-319

Juji, T., Matsuki, K., Tokunaga, K., Naohara, T. and Honda, Y, (1988) Narcolepsy and HLA in the Japanese. Ann. N. Y. Acad. Sci. 540, 106-114.

KaItin, K. I., KildufF, T. S. and Dement, W. C. (1986) Evidence for excessive sleepiness in canine narcoleptics. Electroencephalogr. clin. Neurophysiol. 64, 447-454

Kessler, S., Gullleminault, C. and Dement, W. (1974) A family study of 50 REM narcoleptics. Acta neurol. scand. 50, 503-512.

KildufF. T. S., Bowersox, S. S., Kaitin, K. I., Baker, T. L., Cearenello, R. D. and Dement W. C. (1986) Muscarinic cholinergic receptors and the canine model of narcolepsy. Sleep 9 , 102-106

Kish, S. J., Mamelak, M., Slimovitch, C. et al. (1992) Brain neurotransmitter changes in human narcolepsy. Neurology 42, 229-234.

Kramer, R. E., Dinner, D. S., Braun, W. E., Zachary, A. and Teresi, Teresi, G. A. (1987) HLA-DR2 and narcolepsy. Arch. Neurol. 44, 853-855.
KushidA, C. A , BAKER, T. L. and Dement, W. C. (1985) Electroencephalographic correlates of cataplectic attacks in narcoleptic canines. Electroencephalogr. clin. Neurophysiol. 61, 61-70.

Kuwata, S., Tokunaga, K., Jin, F.. Juji, T., Sasaki. T. and Honda, Y. (1991) Narcolepsy (correspondence). New Engl. J. Med. 324, $271-272$

LAI, Y. Y. and SIEGEL, J. M. (1988) Medullary regions mediating atonia. J. Neurosci. 8, 4790-4796

LAI, Y. Y. and SIEGEL, J. M. (199!) Pontomedullary glutamate receptors mediating locomotion and muscle tone suppression. $J$. Neurosci. 11, 2931-2937.

Langdon, N., Welsh, K. I., VanDaM, M., Vaughan, R. W. and PARKES, D. (1984) Genetic markers in narcolepsy. Lancet 2, $1178-1180$.

Langdon, N., Shindler, J., Parkes, J. D. and Bandak, S. (1986) Fluoxetine in the treatment of cataplexy. Sleep 9, 371--373.

LAvie, P., So, A. K. L. and Peled, R. (1987) Narcolepsy is a rare disease in Israel. Sleep 10, 608-609.

Lock, C. B., So, A. K. L., Welsh, K. I., PARkes, J. D. and TrowsDALE, J. (1988) MHC Class II sequences of an HLA-DR2 nar coleptic. Immunogenetics 27, 449-455.

lucas, E. A., Foutz, A. S., Dement, W. C. and Mitler, M. M (1979) Sleep cycle organization in narcoleptic and normal dogs Physiol. Behav. 23, 737-743.

Matsuki, K., Grumet, F. C., Lin, X., Gelb, M., Gulleminault, C., Dement, W. C. and Mignot, E. (1992) DQ (rather than DR) gene marks susceptibility to narcolepsy. Lancet 339, 1052.

Mignot, E., Guilleminault, C., Bowersox, S., Rappaport, A. and DEMENT, W. C. (1988) Role of central alpha-1 adrenoceptors in canine narcolepsy. $J$. clin. Invest. 82, 885-894.

Mignot, E., Guilleminaul, C., Bowersox, S. et al. (1989) Central alpha 1 adrenoceptor subtypes in narcolepsy cataplexy: a disorder of REM sleep. Brain Res. 490, 186-191.

Mignot, E., Hunt Sharp, L., Arrigoni, J., Nishino, S., Gull.eminaul. T, C., Dement, W. C. and Ciarenello, R. (1991a) Gene dosage effects in canine narcolepsy: induction of cataplexy-like behaviors in heterozygous dogs after drug challenge. Sleep Res. 20, 294.

Mignot, E., Wang, C., Rattazzi, C., Gaiser, C. Lovett, M. Guilleminault, C., Dement, W. C. and Grumet, F. C. (1991b) Genetic linkage of autosomal recessive canine narcolepsy with a mu immunoglobulin heavy-chain switch-like segment. Proc, natn Acad. Sci. U.S.A. 88, 3475-3478

Miller, J. D., Faull, K. F., Bowersox, S. S. and Dement, W. C. (1990) CNS monoamines and their metabolites in canine narcolepsy: a replication study. Brain Res. 509, 169-171

Mitler, M. M. and Dement. W. C. (1977) Sleep studies on canine narcolepsy: pattern and cycle comparisons between affected and normal dogs. Electroencephalogr. clin. Neurophysiol. 43, 69 I-699.

MONTPlaisiR, J. and GodBout. R. (1986) Nocturnal sleep of narcoleptic patients revisited. Sleep 9, 159-161.

MONTPLAISIR, J. and PolRIER, G. (1987) Narcolepsy in monozygotic twins. Neurology 37, 1089.

Montplaisir, J., DeChamplain, J., Young, S. N. et al. (1982) Narcolepsy and idiopathic hypersomnia: biogenic amines and related compounds in CSF. Neurology 32, 1299-1302

Motoyama, M., Kilduff, T. S., Lee, B. S. M., Dement, W. C. and MCDEvitT, H. O. (1989) Restriction fragment length polymor phism in canine narcolepsy. Immunogenetics 29, 124-126.

Neely, S., Rosenberg. R., Spire, J.-P., Antel, J. and ARnason, B. G. W. (1987) HLA antigens in narcolepsy. Neurology 37, $1858-1860$.

Nishino, S., Mignot, E., Fruhstorfer, B., Dement, W. C. and HAYalshi, O. (1989) Prostaglandin E2 and its methyl ester reduce cataplexy in canine narcolepsy. Proc natn. Acad Sci. U.S.A. 86, 2483-2487

Nishino, S., HaAk, L., Sheperd, H., Guilleminalut, C., Sakal, T. Dement, W. C. and Mignot, E. (1990) Effects of central alpha2 adrenergic compounds on canine narcolepsy, a disorder of rapid eye movement sleep. J. Pharmac, exp. Ther. 253, $1145-1152$

Nishino, S., Arrigoni, J., Valtier, D., Miller, J. D., Gullleminault, C., Dement, W. C. and Mignot, E. (1991) Dopamine D2 mechanisms in canine narcolepsy. J. Neurosci. 11, 2666-2771.

Nishino, S., Arrigoni, J., Shelton, J., Dement, W. C. and Mignot, E. (1992) Further analysis of the effects of serotonergic and 
noradrenergic uptake inhibitors on canine cataplexy. Sleep Res. 21, 66.

Nishino, S., Arrigoni, J., Shelton, J., Fruhstorfer, B., GullleminAult, C., Dement, W. C. and Mignot, E. (1992) Further characterization of the alpha-1 receptor subtype involved in the regulation of cataplexy. Sleep Res. 21, 245.

Olerup, O., Schaffer, M., Hillert, J. and Sachs, C. (1990) The narcolepsy-associated DRw15, DQw6, Dw2 haplotype has no unique HLA-DQA or -DQB restriction fragments and does not extend to the HLA-DP subregion. Immunogenetics 32, 41-44.

Parkes, J. D., Fenton, G., Struthers, G. el al. (1974) Narcolepsy and cataplexy. Clinical features, treatment and cerebrospinal fluid findings. Quart. J. Med. 43, 525-526.

Rechtschaffen, A., Wolpert, E. A., Dement, W. C., Mitchell, S A. and Fisher, C. (1963) Nocturnal sleep of narcoleptics. Electroencephalogr. clin. Neurophysiol. 15, 599-609.

Reid, M. S., Geary, J. N., Siegel, J. S., Dement, W. C. and Mignot, E. (1992) Acetylcholine release in the medial pontine reticular formation is enhanced during cataplexy in the narcoleptic canine. Sleep Res. 21, 253.

Renaud, A., Nishino, S., Arrigoni, J., Gulleminault, C., Sakai, T., Dement, W. C. and Mignot, E. (1991) Effects of selective monoamine uptake inhibitors and release enhancers on canine cataplexy. Sleep Res. 20, 76.

Rosenthal, L., Zorick, F., Merlotti, L., Wittig, R., Roehrs, T and RoTH, T. (1990) Signs and symptoms associated with cataplexy in narcolepsy patients. Biol. Psych. 27, 1057-1060.

Rubin, R. L., Hajdukovich, R. M. and Mitler, M. M. (1988) HLADR2 association with excessive somnolence in narcolepsy does not generalize to sleep apnea and is not accompanied by systemic autoimmune abnormalities. Clin. Immun. Immunopath. 49, $149-158$.

SAKAI, K. (1988) Executive mechanisms of paradoxical sleep. Arch. Ital. Biol. 26, 239-257.

Schenck, C. H., Bundile, S. and Mahowald, M. H. (1989) Narcolepsy, loss of REM atonia and the REM sleep behavio disorder: a polysomnographic and clinical report on 10 patients. Sleep Res. 18, 300.
SteGEL, J. M. (1989) Brainstem mechanisms generating REM sleep. In: Principles and Practice of Sleep Medicine, pp. 104-120. Eds. M. H. KRYger, T. Roth and W. C. Dement. WB Saunders: Philadelphia.

SIEGEL, J. M., NiEnhuIs, R., FAHRINGer, H. M. et al. (1991) Neuronal activity in narcolepsy-Identification of cataplexy-related cells in the medial medulla. Science 252, 1315-1318.

Singh, S. M., George, C. F. P., Kryger, M. H. and Jung, J. H. (1990) Genetic heterogeneity in narcolepsy. Lancet 335, 726-727.

Strohmaier, P., Mueller-Eckhardt, G. and Meier-Ewert, K. (1988) Cellular approach for detecting narcolepsy-specific alterations in DR2 haplotypes. Hum. Immun. 22, 221-225.

TAKaHASH, Y. and Jimbo, M. (1963) Polygraphic study of narcoleptic syndrome, with special reference to hypnagogic hallucinations and cataplexy. Folia Psychiatr. Neurol. Jpn. (Suppl.) 7, 343-347.

Uryu, N., Maeda, M., Nagata, Y., Matsuki, K., Juj, T., Honda, Y., Kawal, J., ANDO, A., Tsujl, K. and INoko, H. (1989) No difference in the nucleotide sequence of the $\mathrm{DQ}(\mathrm{beta}) 1$ domain between narcoleptic and healthy individuals with DR2, Dw2. Hum. Immun. 24, 175-181.

VanNi-Mercier, G., Sakai, K., Lin, J. S. and Jouvet, M. (1989) Mapping of cholinoceptive brainstem structures responsible for the generation of paradoxical sleep in the cat. Arch. Ital. Biol. 127, 133-164

Velazquez-Moctezuma, J, Gillin, J. C. and Shiromani, P. J. (1989) Effect of specific M1, M2 muscarinic receptor agonists on REM sleep generation. Brain Res. 503, 128-131.

Velazquez-Moctezuma, J., Shalauta, M., Gillin, J. C. and ShiroMANI, P. J. (1991) Cholinergic antagonists and REM sleep generation. Brain Res. 543, 175-179.

VoGEL, G. (1960) Studies in psychophysiology of dreams. III. The dream of narcolepsy. Arch. gen. Psych. 3, 421-428.

Wilner, A., Steinman, L., Lavie, P., Peled, R., Friedmann, A. and BrautbaR, C. (1988) Narcolepsy-cataplexy in Israeli Jews is associated exclusively with the HLA DR2 haplotype. Hum. Immun. 21, 15-22. 